mester, there was one malformed foetus reported. However, irradiation and other cytotoxics had also been used in this case.

Animal experiments have shown that one of the most sensitive periods of inducing foetal abnormalities with 6-mercaptopurine is at implantation (Thiersch, 1954). However, in humans it is rare for the mother to be receiving cytotoxic drugs at the time of conception. The present case is only the fifth in the medical literature, in which this has been reported (Table 1). In this small series no foetal abnormalities were reported, but only two of the five survived.

However, the child in the present report did have a blood picture similar in some respects to a microangiopathic haemolytic anaemia. It is the first report we can find of an abnormal blood picture at birth in a child born to a leukaemic mother, besides a report of maternal leukaemic cells being found in the baby's blood as a result of transplacental passage (Rigby, Hanson \& Smith, 1964). This indeed may be the explanation of the blast cells in the infant's blood in the present case.

Both the nature and cause of the child's peripheral blood picture are difficult to explain. The process did not appear to be acute, in that features were still present after 5 months. The blood urea was normal. The usual causes of a haemolytic anaemia were excluded and no evidence was found to suggest an immune basis. The fact that the blood picture was abnormal from birth suggests that the aetiological factors were active during intra-uterine life, and therefore possibly related to the mother's disease or drug therapy.

\section{Acknowledgments}

We wish to thank Dr F. J. Davidson, M.R.C.P., and Dr H. Greig, and the Medical Superintendent of the King Edward VIII Hospital for permission to publish this case report.

\section{References}

Frenkel, E.P. \& MeYers, M.C. (1960) Acute leukaemia and pregnancy. Annals of Internal Medicine, 53, 656.

Hoover, B.A. \& Schumacher, H.R. (1966) Acute leukaemia in pregnancy. American Journal of Obstetrics and Gynecology, 96, 316.

Merskey, C. \& Rigal, W. (1956) Pregnancy in acute leukaemia treated with 6-mercaptopurine. Lancet, ii, 1268.

Nicholson, H.O. (1968) Cytotoxic drugs in pregnancy. Journal of Obstetrics and Gynaecology of the British Commonwealth, 75, 307.

Parekh, J.G., Shah, K.M. \& Sharma, R.S. (1959) Acute leukaemia and pregnancy. Journal of the JJ Group of Hospitals and Grant Medical College, 4, 49.

Rigby, P.G., Hanson, T.A. \& Smith, R.S. (1964) Passage of leukaemic cells across the placenta. New England Journal of Medicine, 271, 124.

Rothberg, H., Conrad, M.E. \& Cowley, R.G. (1959) Acute granulocytic leukaemia in pregnancy. American Journal of the Medical Sciences, 237, 194.

ThIERSCH, J.B. (1954) The effect of 6-mercaptopurine on the rat foetus and on reproduction of the rat. Annals of the New York Academy of Sciences, 60, 220.

\title{
The auriculo-temporal syndrome
}

\author{
S. S. SHAH \\ M.D. \\ A. P. SHaH \\ M.D., D.V. \& D. \\ H. V. DosHI
M.D. \\ N. D. Patel \\ M.B., B.S.

\section{M.P. Shah Medical College and Irwin Group of Hospitals, Jamnagar, Gujarat State, India}

SwEATING on the lips, forehead and nose, after eating hot spicy foods occurs physiologically in many persons. Gustatory sweating-excessive sweating during eating in the distribution of the auriculotemporal nerve, was described by Frey (1923) in a patient following an infected bullet-wound of the parotid gland. Since then his name has been associated with this condition, although the condition was described earlier by Duphenix (1757), and later by Baillarger (1853) and Weber (1897-98). Gustatory sweating has also been reported in areas supplied by other branches of the trigeminal nerve, by the greater auricular nerve, the supraclavicular nerve and the nervus cutaneous colli (Chisa, Mendelson \& Darnley, 1964).

The auriculo-temporal syndrome has been 
commonly reported after parotid surgery but can also occur after parotitis, penetrating injury of the parotid gland, central nervous system diseases such as syringomyelia, encephalitis and secondary to dorsal sympathectomy (Sutton \& Trippel, 1963).

Freedberg, Shaw \& McManus (1948) were able to collect only thirty-five cases from the literature. However, in recent years it has been recognized as frequent after parotid surgery (Moyse, 1955; LaageHellman, 1957; Patey, 1958). The syndrome is also reported after operation for cervical lymphadenitis, radical neck dissection for malignancy (Coldwater, 1954; Spiro \& Martin, 1967; Mayers \& Conley, 1970 ), and subcondylar osteotomy for prognathism (Chisa et al., 1964).

Here we present a case of auriculotemporal syndrome following tuberculous lymphadenitis.

\section{Case report}

A 45-year-old Hindu female was admitted to the Irwin Group of Hospitals, Jamnagar, on 23 March 1972 for excessive sweating in a sharply defined area on the right auriculo-temporal region for 6 months. There was no history of parotitis or any operation on the neck or parotid region. The patient had had tuberculous lymphadenitis 20 years before.

Physical examination revealed a well developed, fairly nourished middle-aged woman. A $2.5 \mathrm{~cm}$ vertical pigmented scar was seen just behind the angle of the right mandible and $2.5 \mathrm{~cm}$ below the right external auditory meatus. Systemic examination did not reveal any abnormality. The skin over the right auriculo-temporal area was apparently normal. Glistening drops of clear sweat appeared in the distribution of the right auriculo-temporal nerve on eating and in response to standard stimuli like chewing moistened cotton-wool or sucking an acid drop. Sweating was completely abolished by blocking the otic ganglion with $2 \%$ lignocaine and was markedly reduced with previous anaesthetization of the mucous membrane. Intradermal injection of $20 \mu \mathrm{g}$ of atropine sulphate in $0.2 \mathrm{ml}$ abolished gustatory sweating around the injection site but the same amount of saline had no effect. Exposure to heat produced sweating in both auriculo-temporal regions but it was less on the affected side. Full thickness skin biopsy from the affected area did not reveal any abnormality.

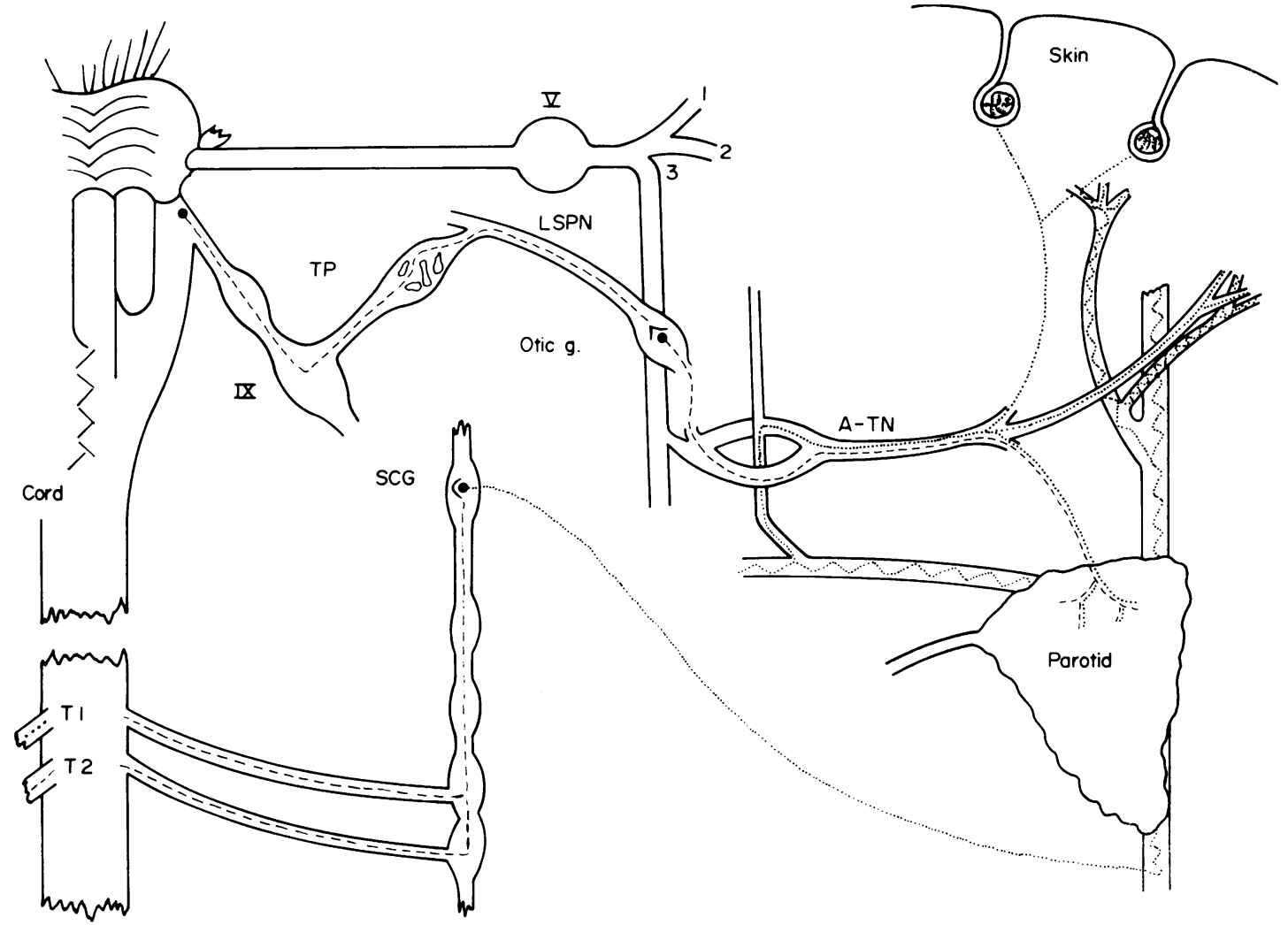

FIG. 1. Schematic diagram of auriculo-temporal syndrome mechanism. - . ., Parasympathetic; ..., sympathetic. V, trigeminal nerve; IX, glossopharyngeal nerve; TP, tympanic plexus; Otic g., ot ic ganglion; LSPN, lesser superficial petrosal nerve; A-TN auriculo-temporal nerve; SCG, superior cervical ganglion. 


\section{Discussion}

Auriculo-temporal or Frey's syndrome is characterized by hyperaemia and perspiration in the area innervated by the auriculo-temporal nerve. Pain in the distribution of the nerve is sometime associated but is not a constant feature. Sweating is generally noted within a short time of the commencement of eating. The degree of sweating varies from being a slight dampness to being profuse enough to cause social embarrassment. This patient did not have hyperaemia or pain.

More recently this syndrome has been found frequently following surgery in the parotid region. Moyse (1955) reported that twenty-two out of thirty patients developed gustatory sweating after parotidectomy, while Laage-Hellman (1957), Patey (1958) and Glaister et al. (1958) reported 120 out of 123 , fifteen out of forty-two and fifteen out of forty-five cases respectively after parotidectomy. However, only a small percentage of these patients had significant symptoms (Turner, 1960). In his review of ninety cases of gustatory sweating, Langenskold (1946) found that some sort of injury to a localized area of head, face and neck existed. One patient developed auriculo-temporal syndrome following tuberculous lymphadenitis which was adequately treated without any operative intervention. The syndrome following such adenitis was reported by Young (1956) but in his patient operative interference was carried out. The average time lag reported is from 6 months to many years. Young reported this duration as 8 years. Our patient developed symptoms 20 years after lymphadenitis.

Various theories are proposed to explain the mechanism of gustatory sweating, the most commonly accepted one being the aberrant regeneration of parasympathetic fibres reaching sympathetic endorgans (Fig. 1). This is supported by the fact that a time-lag of several months to several years is required between the surgical procedure and gustatory sweating. This time lag is probably required for degeneration and later regeneration of injured nerves. This is further supported by the clinical experiment of Glaister et al. (1958) showing abolition of gustatory sweating following blockage of the otic ganglion but persistence of the sweating following blockage of the cervical sympathetic ganglion; and conversely increased salivary secretion from the same side on thermal stimulation. A similar observation was made in our patient after blockage of the cervical sympathetic and otic ganglia. Hypersensitivity to acetylcholine of the denervated sweat gland is another theory suggested by Melnikoff \& Melnikoff (1950). Loss of the insulating nerve-sheath leading to crossing of impulses from sympathetic and parasympathetic fibres is yet another proposition (Chorobsky, 1951).
Treatment is generally unsatisfactory. Local measures are generally not useful. Atropine and its substitutes are useful but cannot be continued for long periods because of side-effects. X-ray irradiation of skin can abolish sweating but the dosage required is very high and the skin damage that it produces is a contra-indication. Avulsion of the auricular-temporal nerve abolishes gustatory sweating but recurrence is common, presumably due to regeneration. Interruption of the parasympathetic pathway by removal or section of the glossopharyngeal nerve within the skull is recommended by Gardner \& McCubbin (1956) but is a major operation which one would hesitate to perform for such a condition which produces minor inconvenience.

\section{Acknowledgments}

We are thankful to the Dean, M. P. Shah Medical College and Irwin Group of Hospitals, Jamnagar, for allowing us to publish this paper. We are also thankful to Mr R. M. Pandya, a college photo-artist, for his help.

\section{References}

Baillarger (1853) Quoted by Spiro, R.H. \& Martin, H.

Chisa, N., Mendelson, C.G. \& Darnley, J.D. (1964) Auriculo-temporal syndrome. Archives of Dermatology, 90, 457.

ChOROBSKy, J. (1951) Syndrome of crocodile tears. Archives of Neurology and Psychiatry, 65, 299.

Coldwater, K.B. (1954) Treatment of auriculo-temporal syndrome. Archives of Surgery, 69, 54.

DUPHENIX (1757) Quoted by Spiro, R.H. \& Martin, H.

FreedberG, A.S., Shaw, R.S. \& McManus, M.J. (1948) The auriculotemporal syndrome: A clinical and pharmacological study. Journal of Clinical Investigations, 27, 669.

FreY, L. (1923) Le syndrome du nerf auriculo-temporal. Review Neurologica, 30, 97.

GARDNER, W.J. \& McCubBin, J.W. (1956) Auriculotemporal syndrome. Gustatory sweating due to misdirection of regenerated nerve fibres. Journal of the American Medical Association, 160, 272.

Glaister, D.H., Hearnshaw, J.R., Heffron, P.F., Peck, A.W. \& Patey, D.H. (1958) The mechanism of postparotidectomy gustatory sweating. The auriculo-temporal syndrome. British Medical Journal, 2, 942.

LAAGE-HellmaN, J.E.(1957) Gustatory sweating and flushing after conservative parotidectomy. Acta oto-laryngolica, 48, 234.

LANGENSKold, A. (1946) Gustatory local hyperhydrosis, following injuries in the parotid region. Acta chirurgica scandinavica, 93, 294.

MAYERS, E.N. \& CoNLEY, J. (1970) Gustatory sweating after radical neck dissection. Archives of Otolaryngology, 91, 534.

Melnikoff, S.M. \& Melnikoff, J. (1950) Gustatory hyperhydrosis on the left knee. Journal of the American Medical Association, 142, 901 .

Moyse, P. (1955) A propos de 200 tumeurs parotidiennes operées. Mémoires de l'Académie de chirurgie, 81, 999.

PATEY, D.H. (1958) Note on surgical consideration-the mechanism of post-parotidectomy gustatory sweating. The auriculo-temporal syndrome. British Medical Journal, 2, 942 .

SPIRO, R.H. \& MARTIN, H. (1967) Gustatory sweating following parotid surgery and radical neck dissection. Annals of Surgery, 165, 118. 
SutTon, T.W. \& TRIPPEL, O.H. (1963) Gustatory sweating. Journal of the American Medical Association, 183, 690.

TURNER, J.C. (1960) Auriculo-temporal (Frey) syndrome occurring after parotid surgery. Surgery, Gynaecology and Obstetrics, 111, 564.
Weber, F.P. (1897-98) Quoted by Glaister et al.

YouNG, A.G. (1956) Unilateral sweating of the submental region after eating (chorda tympani syndrome). British Medical Journal, 2, 976. 